\title{
Hydraulic Fracturing Tight Reservoirs: Rock Mechanics and Transport \\ Phenomena
}

\author{
Hazim Abass, Chris Lamei, and Kaveh Amini, and Tadesse Teklu \\ Petroleum Engineering Department \\ Colorado School of Mines
}

\begin{abstract}
Conventional reservoirs have been fracture stimulated using acid fracturing and proppant fracturing. Acid fracturing is performed to improve well productivity in acid-soluble formations such as limestone, dolomite, and chalk. Hydrochloric acid is generally used to create an etched fracture, which is the main mechanism for maintaining the fracture open during the life of a well. Proppant fracturing is an alternative option that has been applied in carbonaceous and siliceous formations. There is no quantitative method to provide an answer of whether acid fracturing or proppant fracturing is an appropriate stimulation method for a given carbonate formation. How rock mechanics can be applied to decide on what method is more effective? Laboratory experiments have been performed to simulate acid etched to study the effect of elastic, plastic and viscoelastic rock behavior and their effects on fracture conductivity. Comparison of acid vs. proppant fracturing conductivity in carbonate formation is presented.
\end{abstract}

Fracturing low permeability reservoirs is totally different than fracturing tight formations. The fracture geometry required in low permeability reservoirs need to be planar, conductive and penetrating deep in the reservoir. Fracture complexity in these reservoirs is to be avoided for optimum stimulation treatment. However, in fracturing tight formation, a complex fracture network is desirable for better recovery. Creating multiple fractures in horizontal wells without the use of mechanical intervention, is becoming essential especially in tight gas reservoirs. We have learned how to initiate hydraulic fractures into a specific direction and place as many fractures as desired in horizontal wells but with casing and perforation. The challenge now is to initiate weak point across the horizontal well such that fracturing fluid will initiate a fracture there. How rock mechanics has been applied to achieve this objective? We are fracturing tight gas sand in harsh environment, at depth more than $18000 \mathrm{ft}$, of temperature close to $400{ }^{\circ} \mathrm{F}$, and one can figure out the extreme in-situ stresses relevant to this depth.

When the reservoir pressure decreases, the elastic displacement in response to the increase in effective stress will cause natural fractures to close leading to a decline in reservoir productivity. 
The matrix medium feeds the natural tensile fractures which carry the fluids to the wellbore. The decline in conductivity with increasing effective stress should follow a logical declining rate to support a given production rate. How the concept of effective stress has been applied to understand the stress-dependent conductivity of various conductive components of a given reservoir? Rock mechanics testing of these stress sensitive reservoirs becomes vital to optimize fracturing tight formations.

Economical production from tight reservoirs, including shale gas and shale oil formations, requires horizontal well drilling and massive proppant hydraulic fracturing stimulation. The stimulation involves generating sufficient fractures network or stimulated reservoir volume (SRV), which is achieved by placing optimized stimulation treatments along the horizontal section of wellbores ideally drilled from multi-well pads to increase the production rate and ultimate recovery. Hydraulic fracturing in naturally fractured formations is characterized by generating a fractures' network that should be designed for in extremely low permeability of unconventional reservoirs. Fractures should extensively reach shale matrix to achieve commercial gas production. Therefore, production rate and ultimate recovery depend on the size of the created SRV.

The transport phenomena controlling fluid flow through tight formation is no longer sufficient to be modeled by Darcy's flow. Diffusion and imbibition are important transport mechanisms. The concept of osmosis and flow through a semi-permeable membrane component are critical. Additionally, diffusion and a special case of molecular flow due to Knudson effect will be discussed. Conventional reservoir simulation collapses when trying to simulate fluid flow through tight reservoirs. Numerical studies on a hydraulically fractured well to simulate the dynamic processes during fracturing injection, following well shut-in (soaking), and production are discussed.

\section{$\underline{\text { Introduction }}$}

Since the beginning of hydraulic fracturing, many modeling efforts have been made to understand the operation on all disciplines related to the process such as reservoir engineering, fluid mechanics, rock mechanics, material science, and chemistry. Modeling was performed at many aspects; mathematical, lab scale experimentation and field scale testing. This chapter presents the experimental modeling which was the first tool to understand hydraulic fracturing.

The process of Hydraulic fracturing requires understanding near wellbore phenomena to make an engineering design for a stimulation treatment. Experimental modeling lends itself to such application where a small-scale testing reasonably provides insight on how a fracture initiates and propagates from a circular hole. Rock samples obtained from outcrops or synthetic samples may be 
used to understand the effect of a wellbore and near wellbore stress field on a fracture geometry generated from hydraulically pressurizing the well until a tensile failure occurs. There are distinct features associated with any rock formation such as; homogenous or heterogeneous, brittle or ductile, consolidated or unconsolidated, permeable or tight, and intact or naturally fractured. These features greatly affect hydraulic fracturing results that can be modeled in laboratory scale testing to understand many concepts that are vital to design effective fracture-stimulation treatments. The main logical difference between fracturing conventional and unconventional reservoirs is that in conventional reservoirs a fracture is introduced for the hydrocarbon to sense and flow toward it; while in unconventional reservoirs, a fracture is to reach where the hydrocarbon is located. Therefore, hydraulic fracturing in relatively permeable reservoirs is mostly used for modifying the fluid-flow pattern in the reservoirs; while in tight formations it is aimed at shearing existing micro fractures to get closer to the trapped hydrocarbon, and bringing more reservoir volume in contact with created fracture network.

The fundamental experimental modeling in hydraulic fracturing is presented to provide understanding of the principles of hydraulic fracture propagation. Then, more recent and advanced experimental modeling is provided, which include fracturing fluid interaction with the rock at pore scale, and recent advances in creating large fractures using less water or eliminating water all together. Economical production from tight reservoirs, including shale gas and shale oil formations, requires horizontal wells with multi-stage fracturing. The fracturing treatment involves generating sufficient fractures network or stimulated reservoir volume (SRV), which is achieved by placing optimized stimulation treatments along the horizontal section of wellbores ideally drilled from multiwell pads to increase production rate and ultimate recovery. Induced fractures should extensively reach tight matrix to achieve commercial gas production. Therefore, production rate and ultimate recovery depend on the size of the created SRV.

\section{Fracture Geometry}

The effect of wellbore placement relative to the in-situ stress field controls the fracture geometry generation as shown in Figure (1) [1]. Fracture complexity in conventional reservoirs is to be avoided for optimum stimulation treatment. However, in fracturing shale formation, a complex fracture network is desirable for effective stimulation. Let's start with fracturing conventional reservoirs. In conventional resources creating multiple fractures often is undesirable and can lead to creating narrow fractures more prone to screen out, increasing in fluid leak off, and operational problems due to reoriented fractures. Multiple fractures in conventional reservoirs are mainly created 
due to the short length of the perforation interval and perforation orientation. Non-planar fractures show limited communication with the wellbore due to reduced number of communicating perforations, reduced width, and tortuosity created near the wellbore [33]. All these issues are not of concern when it comes to fracturing tight reservoirs.

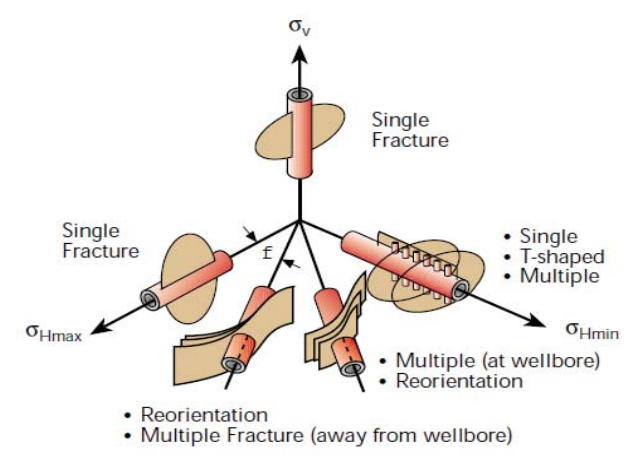

Fig. (1) Planar and nonplanar fracture geometries, [1].

\section{Planar Geometries}

Planar fractures result when the wellbore is aligned with one of the principal stresses. Usually, the created fracture is single and has a clear and wide connection to the wellbore through the perforation or even in an open hole completion. Fig. Shows a typical planar longitudinal fracture.

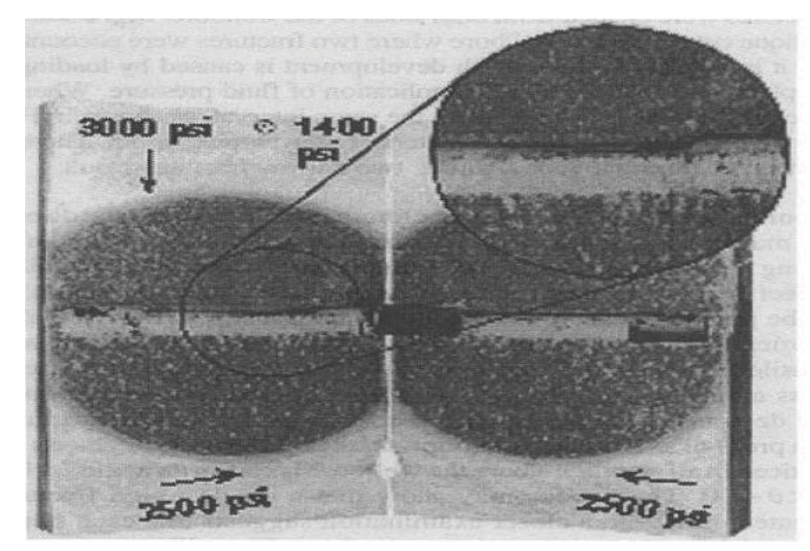

Fig. (2) A typical planar fracture created during lab experimental modeling, [1].

\section{Non-Planar Geometries}

Non-planar fractures in conventional hydraulic fracturing treatment are categorized as multiple fractures, reoriented fractures creating steps, and T-shaped fractures. When multiple fractures are created (they usually created due to perforation orientation which will be discussed later in the chapter) they result in reduced width. Fig. shows multiple fractures initiated from a deviated cased 
hole and an open hole. Although it might not be visible in the picture, this test resulted in multiple fractures initiated from each perforation. These propagating fractures ultimately formed one fracture as they propagated away from the wellbore.

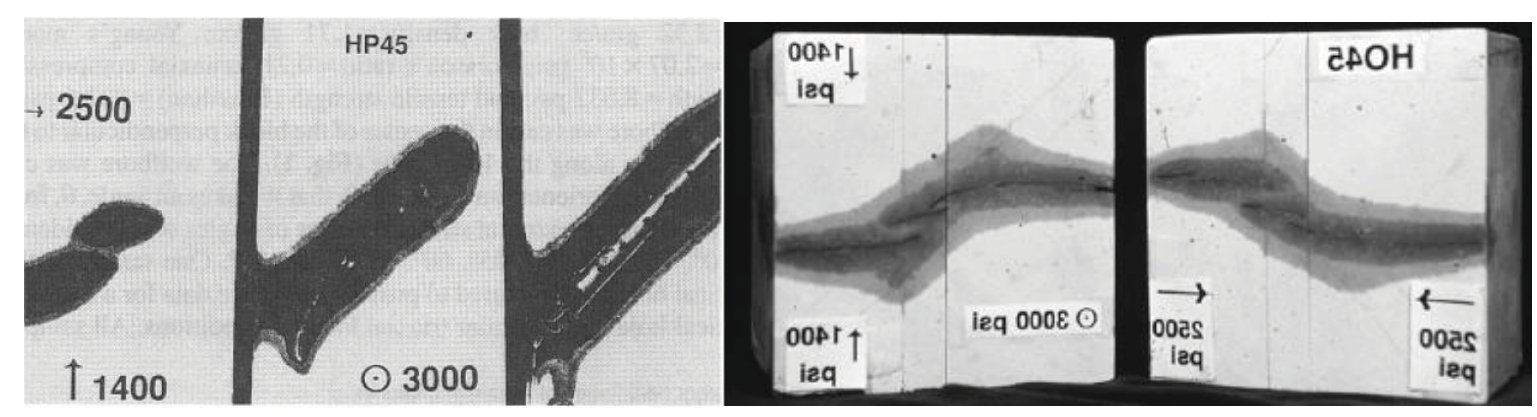

Fig. (3) multiple fractures from a cased wellbore (left) and open hole (right), [1].

The segmentation nature of fracture was also observed in larger-scale treatment [25]. in a mine-back observation discovered the six different perforations created five separate fractures Fig. (44). However, in conventional reservoirs segmented fracture are often treated as a single planar fracture.

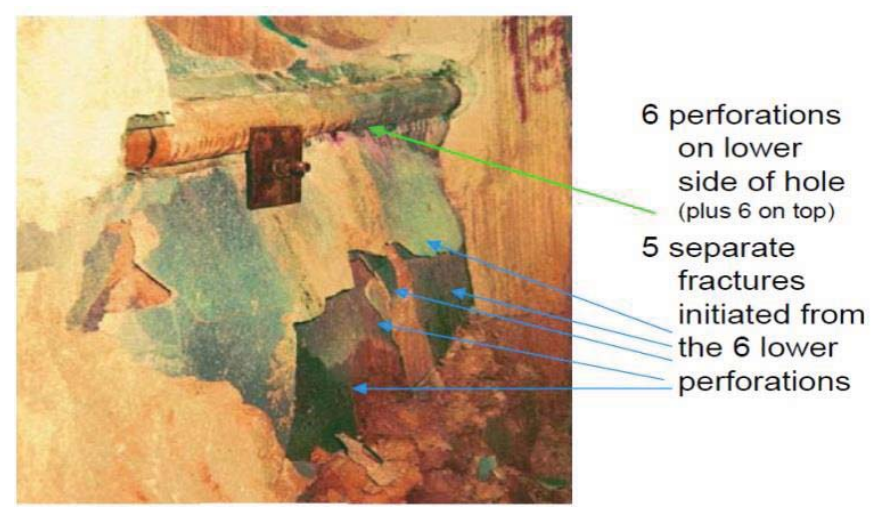

Fig. (4) Back mining observation of multiple fractures propagating from a wellbore,[25]

Another complexity which has been observed in lab testing is generating multiple fractures. This process happens when a fracture initiates at an angle to the least principal stress. Then, multiple fractures at the wellbore or near a wellbore may result as the fracture reorients itself to orient itself perpendicular to the minimum principal stress. The reorientation process in fracturing lab-scale rock samples with deviated wells was described by [6] as shown in Figure (5). 


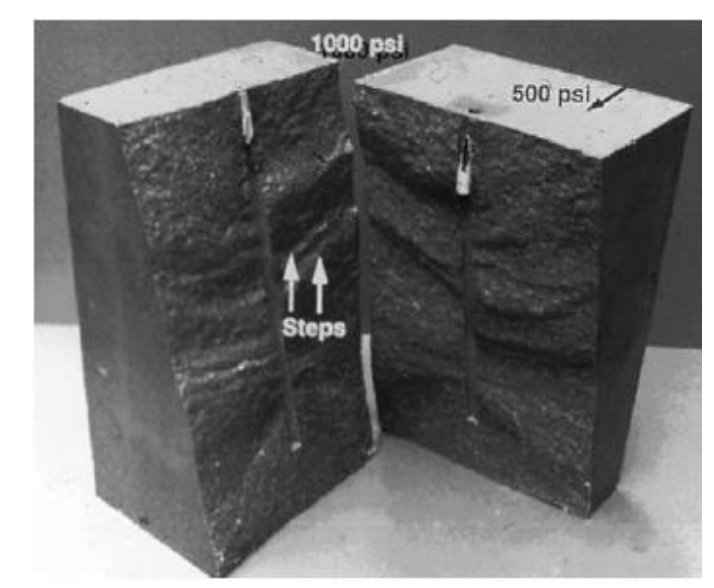

Fig. (5) A fracture tries to reorient itself to be perpendicular to the minimum principal stress [6]

Fig. (6) Shows experimental studies by [36] on the left and by [1] on the right which shows the segmentation nature of the fractures. [36]
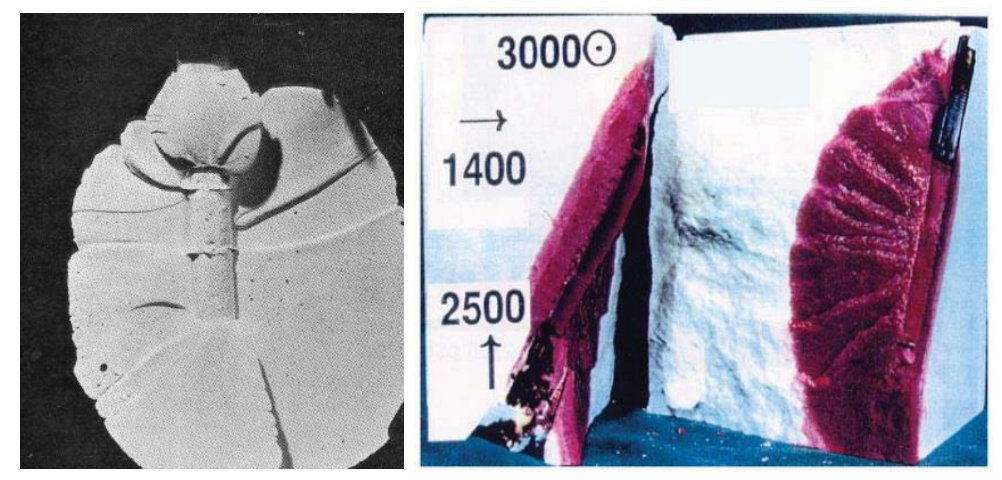

Fig. (6) Segmented fractures are shown in laboratory tests $[6,36]$

Fig. (7) shows multiple fractures resulting from cryogenic fracturing with liquid $\mathrm{N}_{2}$. Created fractures orient themselves to be perpendicular to the direction of least stress. [4]

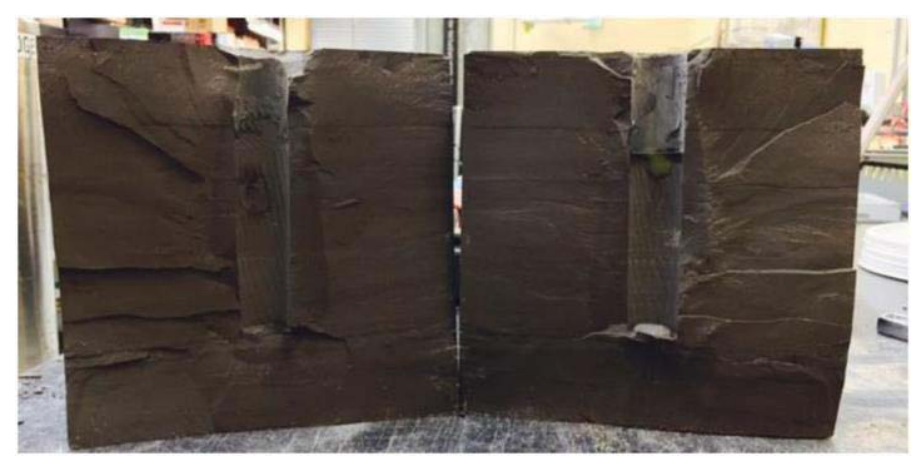

Fig. (7) cryogenic fracturing techniques [4]

Once fracture created, it can change the stress state in the reservoir rock surrounding the fracture, and subsequent fracturing stages can be affected by the new stress field, [33]. Also, different 
mechanisms can affect the shape and propagation of hydraulic fractures including heterogeneity of the rocks and pre-existing fracture seen commonly in unconventional reservoirs, [16]. A fracturing network pattern has been observed in laboratory experiments on shale and coal samples as shown in the Fig ( $8 \& 9)$ respectively.
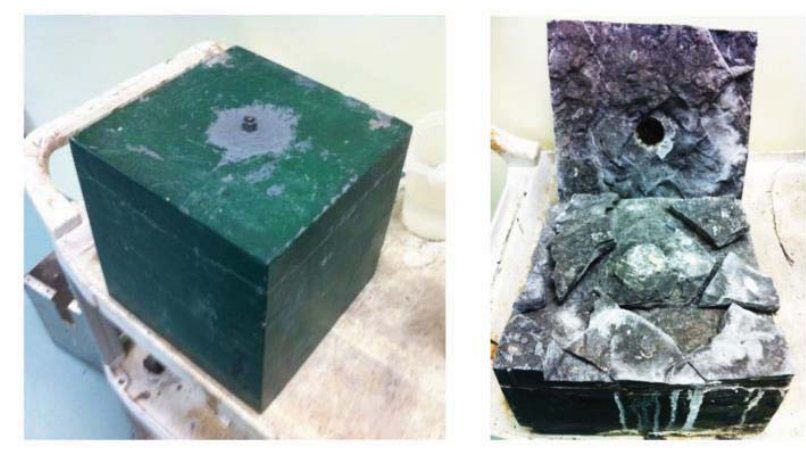

Fig. (8) Pre and Post fracturing results of a shale block sample of 8"x8"x8" [3].

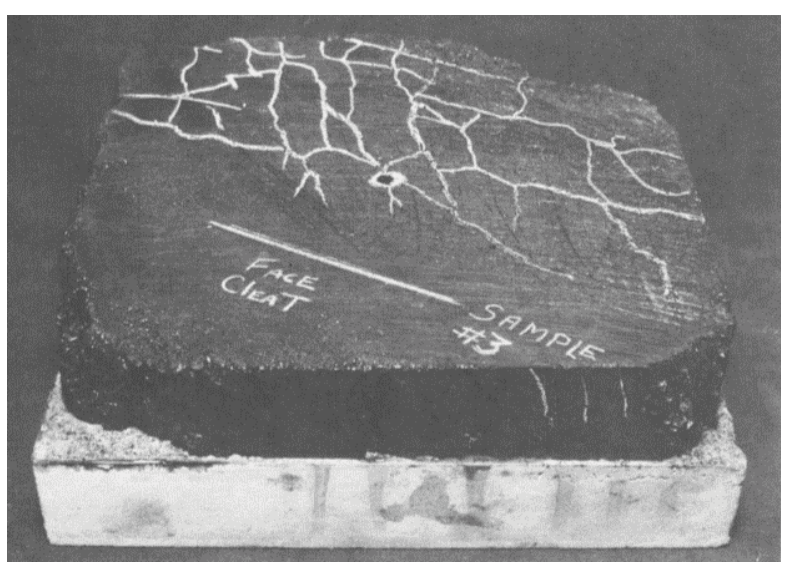

Fig. (9) Hydraulic fractures pattern from fracture blocks of coalbed methane [2].

In shale testing with oriented perforation, Fig.(10) Shows the propagated fracture initiated from the shale sample and through hydrostone sample. 

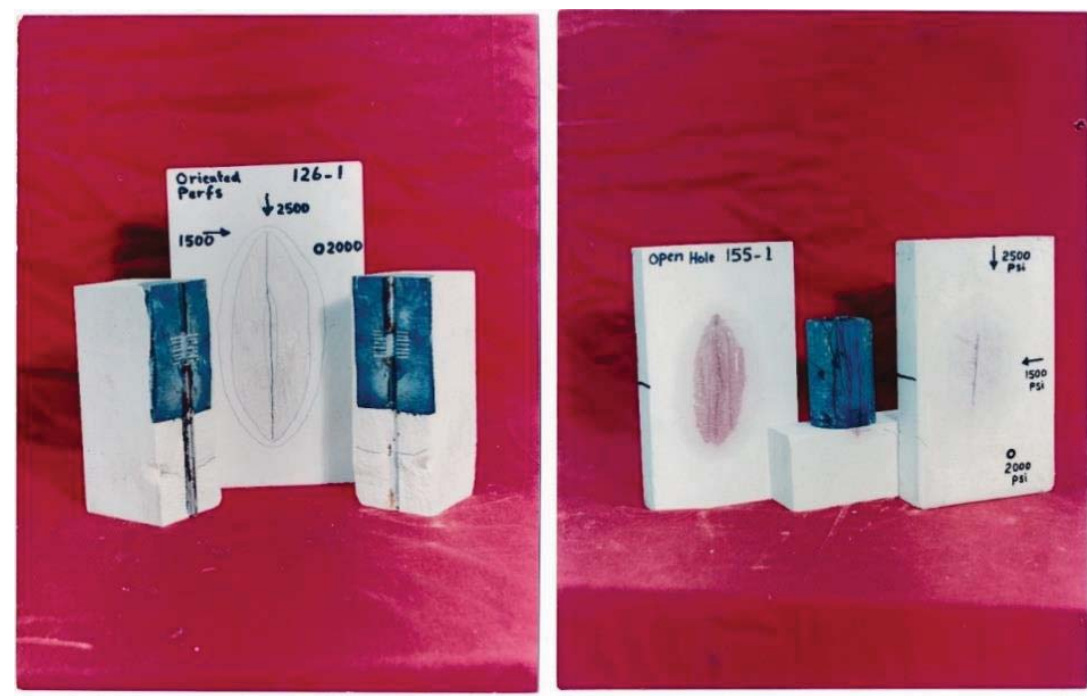

Fig. (10) Oriented perforation (left) versus open hole fracturing (right) in shale sample cast in hydrostone

\section{$\underline{\text { Stimulated Reservoir Volume (SRV) from Microsiesmic }}$}

Creating a more complex network of fractures, could substantially enlarge the created SRV [8]. The creation of SRV and fracture complex network was first discussed in Barnett shale formation, and their importance of final production was observed. Fig. 11 shows the microseismic mapping of hydraulic fracturing in a vertical well in a shale formation which indicates the creation of complex fracture network [17]. In creating a complex fracture network sliding existing natural fractures is critical. Fluid injection has an impact on the change of friction coefficient and subsequently influencing the sliding of natural fractures during hydraulic fracturing [21, 22].

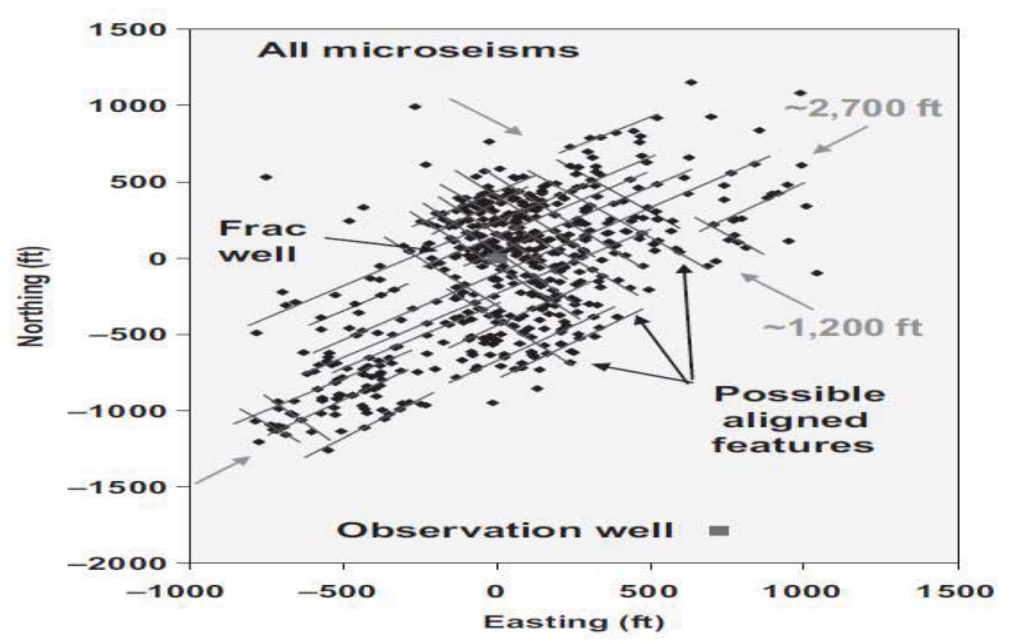

Fig. (11) Microseismic mapping of a fracture network [17] 
To create optimum SRVs, horizontal fracturing with massive hydraulic fracturing treatments which could be up to 30-50 hydraulic fracturing stages was employed. This method, although it was successful in creating a larger SRV, resulted in substantially increasing the treatment cost and complexity regarding water needed and high volume of water waste back from hydraulic fracturing treatments.

\section{Acid or Proppant Fracturing in Tight Carbonate Formation}

Acid fracturing is performed to improve well productivity in acid-soluble formations such as limestone, dolomite, and chalk. Hydrochloric acid is generally used to create an etched fracture, which is the main mechanism for maintaining the fracture open during the life of a well. Proppant fracturing is an alternative option that has been applied in carbonate formations. Acid or proppant fracturing have been used as a standard stimulation method for carbonate formations. There is no quantitative method to provide an answer of whether acid fracturing or proppant fracturing is an appropriate stimulation method for a given carbonate formation. How rock mechanics can be applied to decide on what method is more effective? Laboratory experiments have been performed to simulate acid etched to study the effect of elastic, plastic and viscoelastic rock behavior and their effects on fracture conductivity. Comparison of acid vs. proppant fracturing conductivity in carbonate formation is presented. The result is not always the same and acid or proppant is selected depending on many parameters including rock mechanical properties, stress, temperature, effect of acid on rock mechanical behavior, type of proppant, and many more. Fig. (12) explains how applied rock mechanics and simulated experiments have been used to answer the critical question posted in this section.

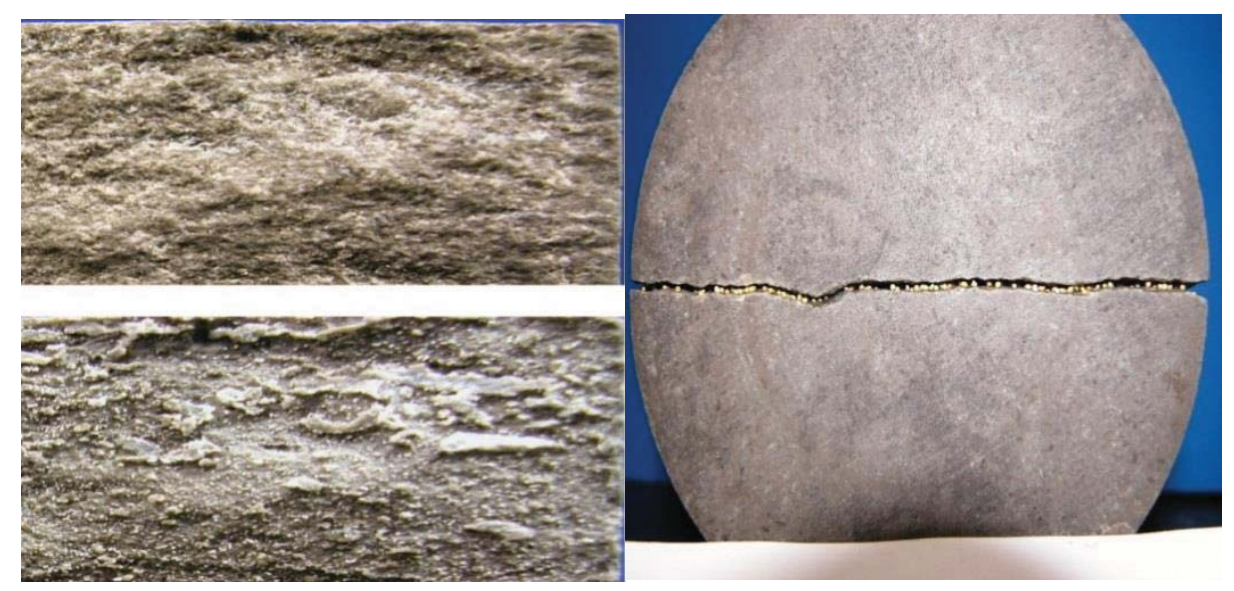




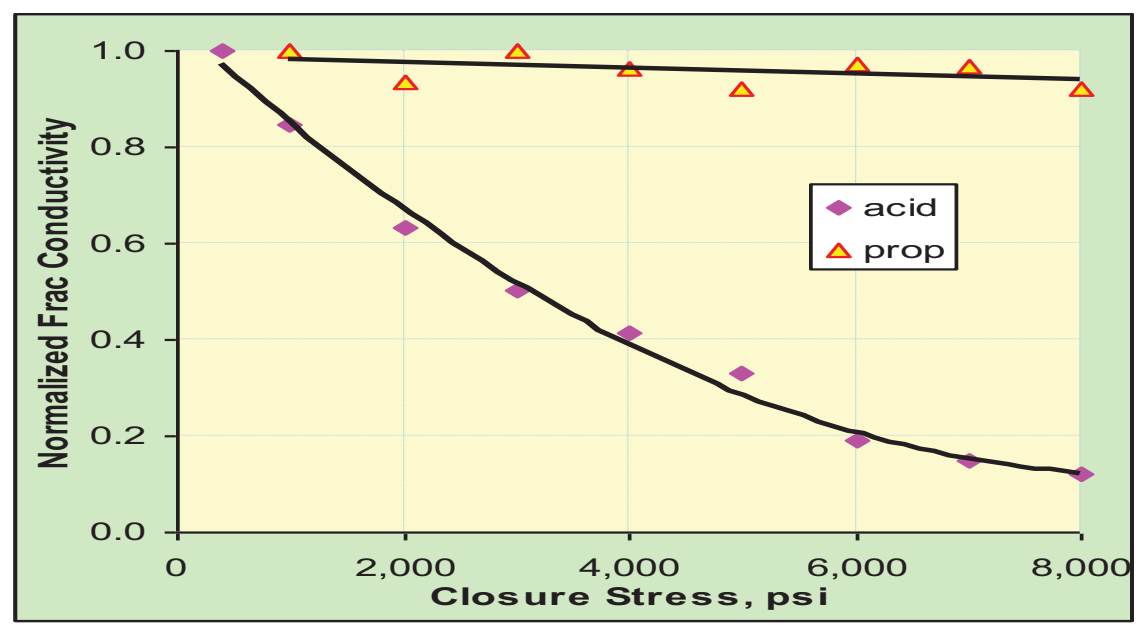

Fig. (12) Acid or proppant fracturing in carbonate formation

\section{Perforation for Fracturing}

Single wide fracture in conventional reservoirs is the superior stimulation technique that can create a conductive path for flow from the matrix to the wellbore. Non-planar fracture geometries fractures adversely affect this objective. Oriented perforation is used to create a single planar fracture. Multiple fracture initiation is considered as complexity in fracturing treatment; thus, they are unfavorable in conventional reservoirs as they often compete against each other resulting in multiple narrow fractures instead of creating one single wide fracture. The same phenomena can be observed in unconventional reservoir hydraulic fracturing treatment. Instead of creating multiple fractures, there might be several natural fractures which can intersect with the induced fracture and create a network of fractures. However, in this case, multiple fracture or fracture network is favorable in tight reservoirs as the scope of hydraulic fracturing demands more fracture to access more volume of the reservoir, [26].

\section{Fracturing Simulators}

Current methods of increasing the SRV often involves increasing the number of hydraulic fractures stages and increasing the total volume and proppant mass which significantly increase fracturing cost. Furthermore, environmental concerns associated with the treatment and disposal of recovered water add to the existing challenges to fracturing tight reservoirs. Fracture simulators were developed as basic models, and they have been rapidly evolving in the last several years. In general, fracture simulators can be divided into several categories: 


\author{
A. 2D Models: Perkin-Kern Nordgren (PKN), Khristianovich-Geertsma-DeKlerk (KGD), Penny \\ shape Frac \\ B. Pseudo-3D Models: M-Frac,StimPlan, FracCade \\ C. Lumped Parameters Models: FracPro \\ D. Fully 3D models: StimPlan, GOHFER, Terra-Frac \\ E. Fully 3D models: Cfrac, Mangrove
}

\title{
Transport Phenomena
}

The most transport related properties that are critical to tight reservoirs are brittleness-ductility characteristics with natural fractures distribution, adsorption/desorption characteristics, stressdependent behavior of matrix and natural fractures, initial water saturation and relative permeability. Natural and induced fractures have an important role in producing from shale formations. Natural fractures properties can be assessed from cores, outcrops, logs, and simulation results based on matching production history. In this part, some theoretical studies are applied for interpretation of some fracture properties in the core plugs [11]. If there is one natural fracture in the middle of the core plug, the fracture porosity and permeability are calculated using the following equations:

$$
\begin{aligned}
& \phi_{f}=\frac{\text { Volume offracture }}{\text { volume of core }}=\frac{4 w_{f}}{10^{4} \pi d} \\
& k_{f}=10^{3} \frac{w_{f}^{2}}{12} \\
& k_{f, \text { eff }}=k_{f} \phi_{f}+k_{m}\left(1-\phi_{f}\right)=k_{f} \phi_{f}+k_{m}
\end{aligned}
$$

The equations are solved together to calculate fracture width, fracture porosity, and fracture intrinsic permeability by having the matrix permeability and the fracture effective permeability.

$$
\begin{aligned}
& w_{f}=\left[30 \pi d\left(k_{f, e f f}-k_{m}\right)\right]^{\frac{1}{3}} \\
& \phi_{f}=\frac{4\left[30 \pi d\left(k_{f, e f f}-k_{m}\right)\right]^{\frac{1}{3}}}{10^{4} \pi d} \\
& k_{f}=10^{3} \frac{\left[30 \pi d\left(k_{f, e f f}-k_{m}\right)\right]^{\frac{2}{3}}}{12}
\end{aligned}
$$

Core plug with a natural fracture Fig (13) may be used to evaluate fracture permeability at various confining stresses to provide stress-dependent permeability in reservoir simulation. Similarly, matrix 
permeability can be evaluated from cores that do not appear to have microfractures.
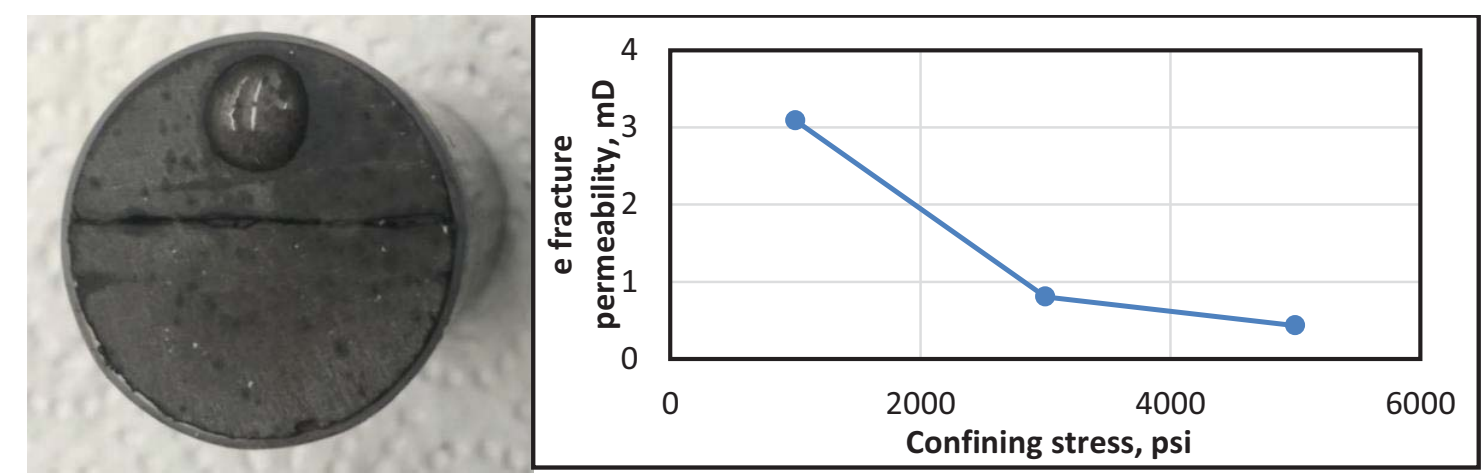

Fig. (13) A fracture passes through a core plug and stress-dependent permeability

While the fracture width is less than 10 microns, the fracture permeability can be as high as several Darcies. However, the effective fracture permeability which shows the conductivity of the fracture system within the whole reservoir can be much less than fracture permeability.

\section{Adsorption and Desorption}

A portion of the gas in place in shale formations is stored or adsorbed on the pore surface of organic materials or Kerogen. As pore pressure declines, the adsorbed gas is desorbed. The adsorption isotherm characteristics is determined in the lab such as that presented in Fig. (14). A curve with the following equation was fitted to the measured data to obtain the Langmuir coefficients VL and PL:

$V=\frac{V_{L} \cdot P}{P+P_{L}}$

Where $\mathrm{V}$ is the adsorbed gas per mass of sample in scf/ton or gmole $/ \mathrm{kg}$, and $\mathrm{P}$ is the pressure. During desorption, gas is released from organic material. Therefore, the Langmuir adsorption coefficients are plotted against TOC as presented in [11].Error! Reference source not found. The fitted lines are used to estimate Langmuir adsorption coefficients in the whole formation. 

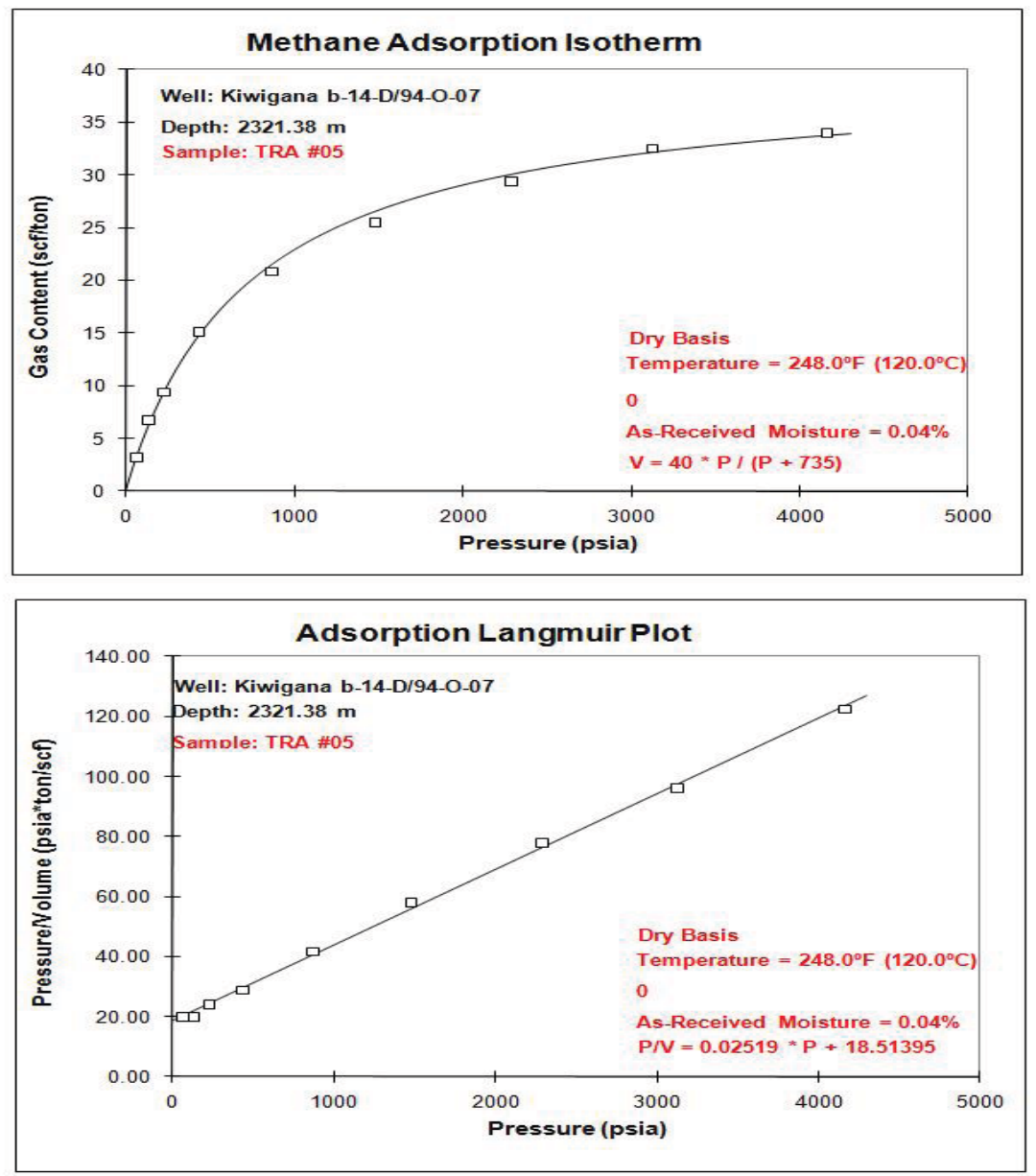

Fig. (14) Methane adsorption isotherm (top) and Langmuir plot (bottom)

\section{Water Saturation}

The saturation data was obtained from TRA report and the arithmetic average values were determined for each flow unit. The small amount of oil was neglected in simulation since there is no report of oil production available. 


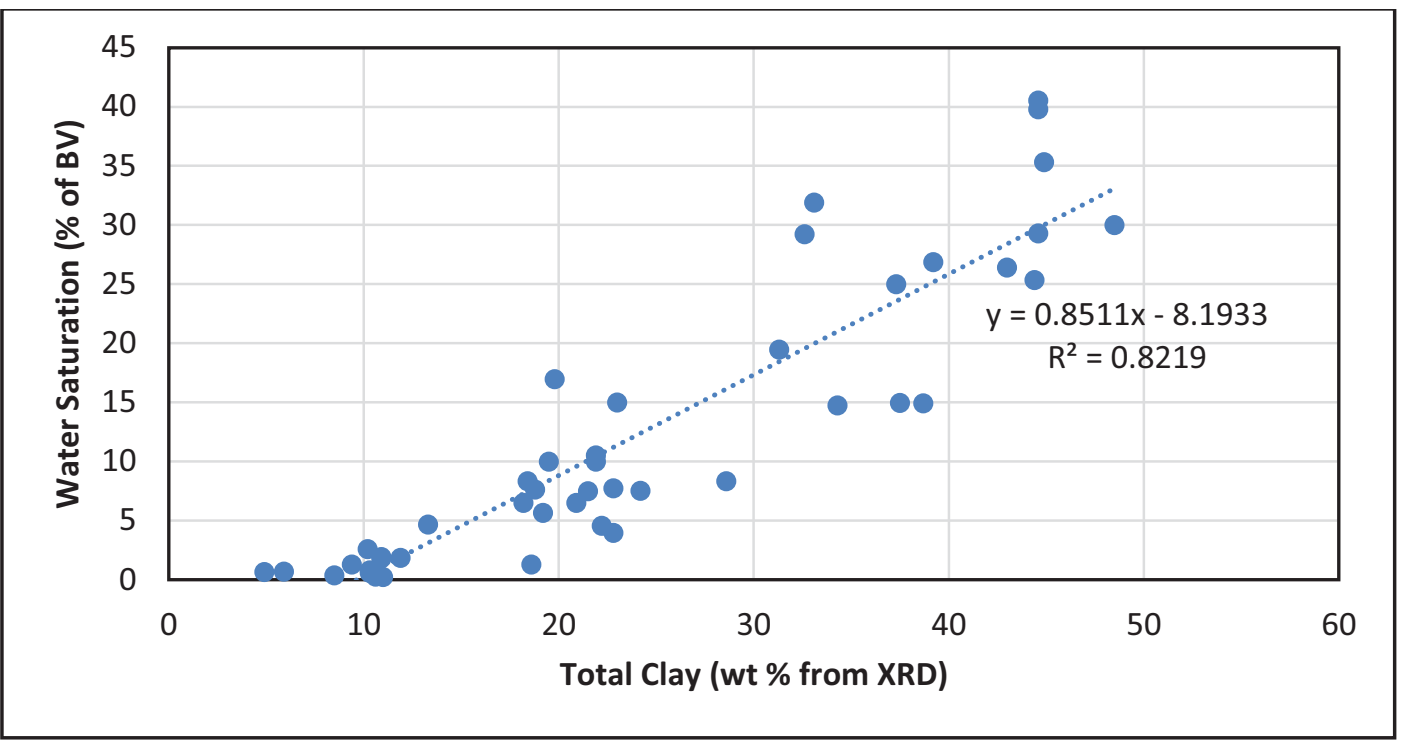

Fig. (15) Water saturation versus total clay based on core tests.

\section{$\underline{\text { Relative Permeability }}$}

One of the parameters that need to be evaluated with history matching is relative permeability. The relative permeability curves extremely affect water production.

\section{Multiphase Flow Analysis from production data}

The purpose of this study is to estimate the effective permeability of water and gas by using the multiphase flow analysis of production data. As it is illustrated in Fig. the reservoir fluids transfer from matrix to natural fractures and from natural fractures to hydraulic fractures and finally flow to the wellbore.

By observing production data, the dominant flow regimes can be recognized in different periods of time. The first flow regime that may be observed is the linear flow in hydraulic fractures. This flow regime is expected to be substituted by the bilinear flow regime as the result of the linear flows in hydraulic fractures and the natural fractures. When the initial flow rate declines and the pressure loss inside the hydraulic fracture becomes negligible, the linear flow regime in natural fractures begins. For the multiphase linear flow analysis in natural fractures, the following equation is used [11]:

$\frac{\Delta p(t)}{q_{\text {total }}(t)}=\frac{4.064\left(\frac{\pi}{2}\right)}{\sqrt{M_{t}}\left(h n_{h f} L_{h f}\right)}\left[\frac{1}{\left(\phi c_{t}\right)_{f+m}}\right]^{\frac{1}{2}} \sqrt{t}+\frac{141.2}{M_{t} h n_{h f}} s_{h f}^{\text {face }}$

Where,

$q_{\text {total }}(t)=q_{g}(t) B_{g}+q_{w}(t) B_{w}$ 
$M_{t}=k_{f, e f f} \lambda_{t}$

$\lambda_{t}=\lambda_{g}+\lambda_{w}$

$\Delta p(t)=p_{i}-p(t)$

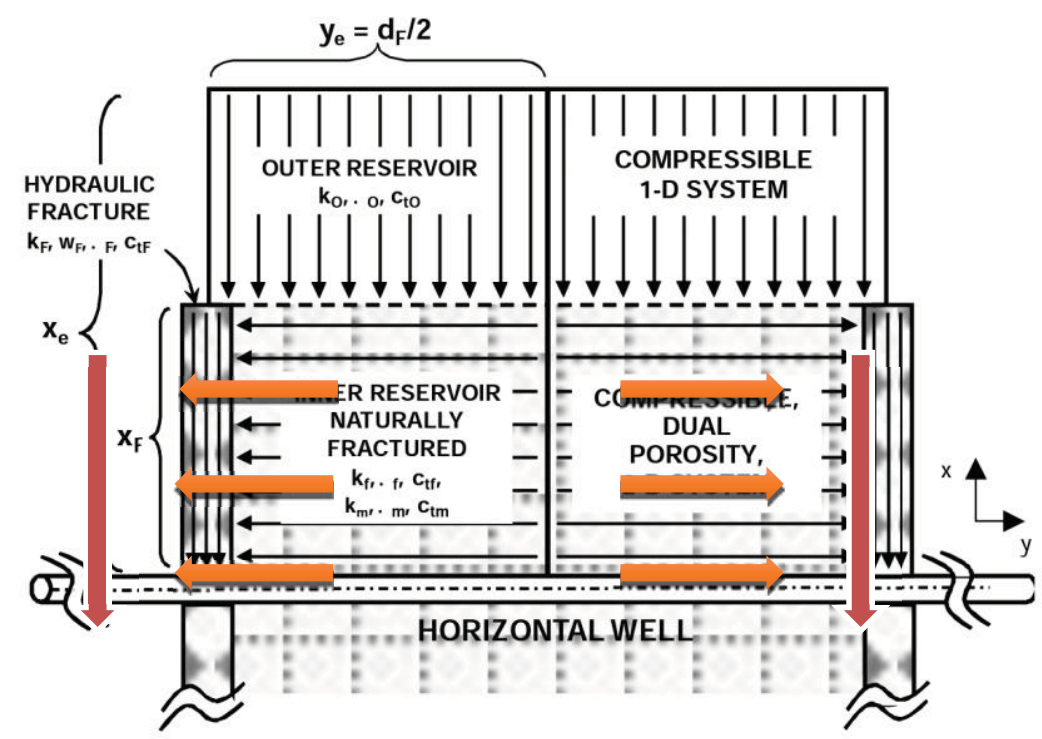

Fig. (16) Schematic diagram of the fluid flow from reservoir into the well

\section{Sensitivity Analysis}

The main purposes of the sensitivity analysis are to understand the effect of different parameters on ultimate recovery. After building a representative base model using any simulator, it is essential to simulate each critical parameter to analyze the sensitivity of that parameter (Fig 17, 18, and 19). For example, the number of stages and clusters in each stage in each length of a horizontal well can be tested for optimization. Perforation and fracturing for SRV then reservoir simulation of SRV are keys in tight reservoirs. 


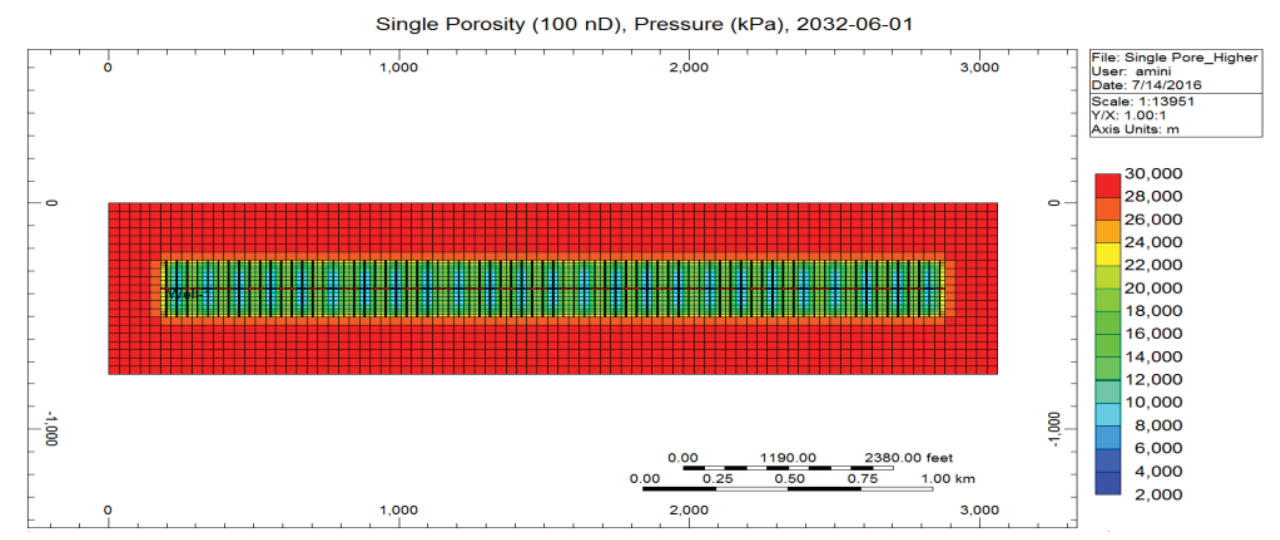

Fig. (17) Single-pore model with $100 \mathrm{nD}$ permeability.

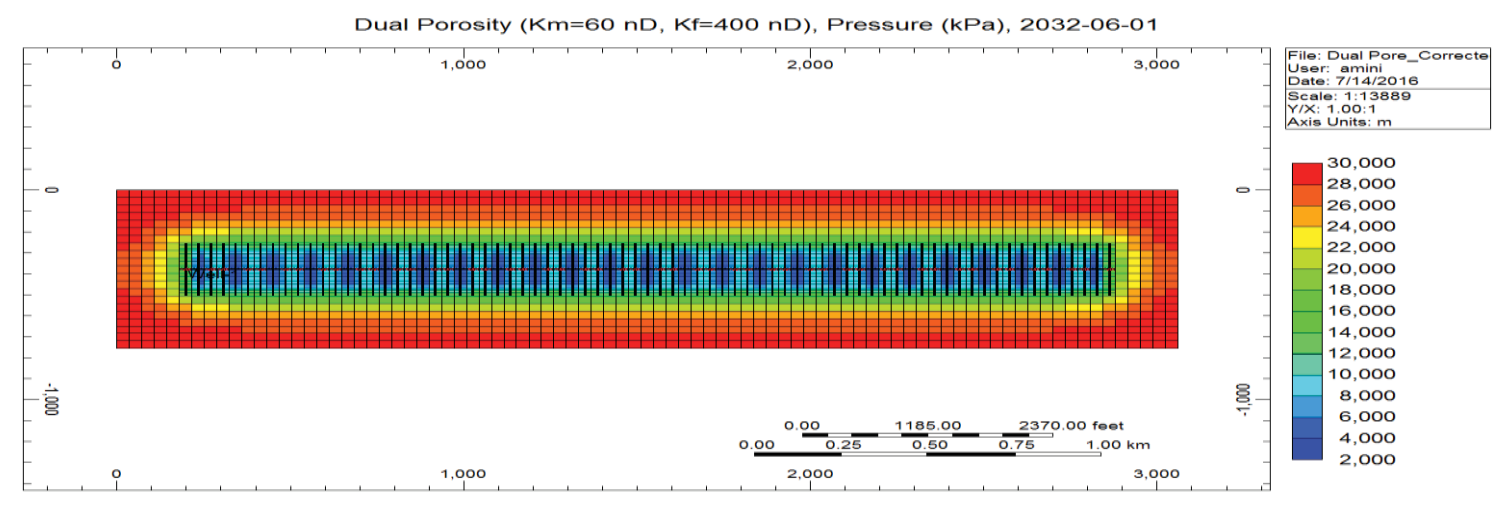

Fig. (18) Dual-porosity model with $60 \mathrm{nD}$ matrix permeability and $400 \mathrm{nD}$ fracture permeability.

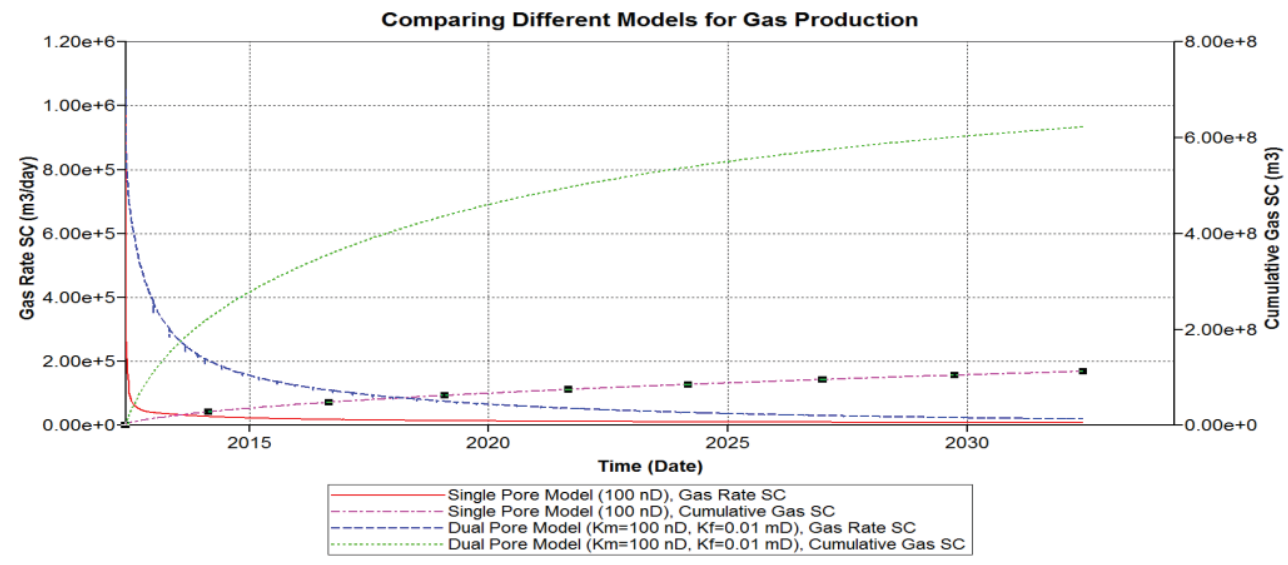

Fig. (19) Comparing the gas production rate and the cumulative gas production for dualporosity and single-porosity models. 


\section{Conclusions}

- The main logical difference between fracturing conventional and unconventional reservoirs is that in conventional reservoirs a fracture is introduced for the hydrocarbon to sense and flow toward it; while in unconventional reservoirs, a fracture is to reach where the hydrocarbon is located.

- Non-planar fractures that reduces communication with a wellbore and tortuosity created near wellbore are avoided in conventional fracturing; however, they are not of concern in fracturing tight reservoirs.

- Perforation and fracturing then reservoir simulation of conventional reservoirs are fundamentally different in design compared to tight reservoirs. Maximizing SRV is affected by well orientation, number of stages, and number of clusters per stage.

- Fracturing materials are also selected for maximum SRV such as the fluid filtrate, diversion, architecture, refracturing, and procedures.

- The most transport properties that are critical to tight reservoirs are brittleness-ductility characteristics with natural fractures distribution, adsorption/desorption characteristics, stressdependent behavior of matrix and natural fractures, initial water saturation and relative permeability.

- Lab results on reservoir cores are critical for an effective fracturing design and reasonable reservoir simulation study. The most important lab testing includes: 1) effect of fracturing fluid filtrate on matrix and natural fractures permeabilities, 2) stress dependent permeability of matrix and natural fractures, 3) mechanical properties to determine rock ductility or brittleness, adsorption isotherm for organic materials, 5) deciding on acid or proppant fracturing in carbonate formation, and 6) optimizing proppant size and concentration.

\section{$\underline{\text { Symbols }}$}

$\mathrm{w}_{\mathrm{f}}$ : fracture width, $\mu \mathrm{m}$,

$\mathrm{d}$ : core plug diameter, $\mathrm{cm}$,

$\phi_{\mathrm{f}}$ : fracture porosity,

$\mathrm{k}_{\mathrm{f}}$ : fracture permeability, md,

$\mathrm{k}_{\mathrm{m}}$ : matrix permeability, md,

$\mathrm{k}_{\mathrm{f} \text {,eff: }}$ effective fracture permeability, md.

$c_{\mathrm{t}, \mathrm{m}}$ : total matrix compressibility, $1 / \mathrm{psi}$ 
$\mathrm{c}_{\mathrm{t}, \mathrm{f}}$ : total fracture compressibility, $1 / \mathrm{psi}$

$\mathrm{h}$ : formation thickness, $\mathrm{ft}$

$\mathrm{k}_{\mathrm{f}, \mathrm{eff}}$ : effective fracture permeability, $\mathrm{mD}$

$\mathrm{p}_{\mathrm{i}}$ : initial reservoir pressure, $\mathrm{psi}$

$\mathrm{q}_{\mathrm{g}}$ : gas production rate, $\mathrm{SCF} /$ day

$\mathrm{q}_{\mathrm{w}}$ : water production rate, $\mathrm{STB} /$ day

$\mathrm{B}_{\mathrm{g}}$ : gas formation volume factor, $\mathrm{RCF} / \mathrm{SCF}$

$\mathrm{B}_{\mathrm{w}}$ : water formation volume factor, RB/STB

$\mathrm{n}_{\mathrm{hf}}$ : total number of hydraulic fractures

$\mathrm{s}_{\mathrm{hf}}^{\text {face }}$ : skin factor at the face of hydraulic fracture connecting to the reservoir

$\mathrm{L}_{\mathrm{hf}}$ : fracture half-length, $\mathrm{ft}$

$\mathrm{t}$ : time, $\mathrm{hr}$

Swr: residual water saturation for water-oil system

Sorw: residual oil saturation for water-oil system

nw: exponent for water relative permeability curve for water-oil system

now: exponent for oil relative permeability curve for water-oil system

$k_{r w}^{*}$ : maximum relative permeability of water in $\mathrm{mD}$

$k_{\text {row }}^{*}$ : maximum relative permeability of oil in $\mathrm{mD}$

$S_{g c}$ : connate (critical gas) saturation

$p(t)$ : bottom-hole pressure at the time $t$.

$C_{\phi f}$ : fracture compressibility

$\alpha f$ : fracture Biot's coefficient

$\mathrm{P}$ : pore pressure. 


\section{$\underline{\text { References }}$}

1. Abass, H. H., Hedayati, S., \& Meadows, D. L. (1996). Nonplanar fracture propagation from a horizontal wellbore: experimental study. SPE Production \& Facilities, 11(03), 133-137.

2. Abass, H. H., Kim, C. M., \& Hedayati, S. (1991). Experimental Simulation of Hydraulic Fracturing in Shallow Coal Seams. Rock Mechanics as a Multidisciplinary Science, 261-270.

3. Al-Nakhli, A. R., Abass, H. H., Khan, M., Hilab, V., \& Rizq, A. (2014). Chemically-Induced Pressure Pulse to Increase Stimulated Reservoir Volume in Unconventional Reservoirs. SPE Unconvnetional Resources Technology, URTec 1922369. Denver, CO.

4. Alqatahni, N. B., Cha, M., Yao, B., Yin, X., Kneafsey, T. J., Wang, L., \& Miskimins, J. L. (2016). Experimental Investigation of Cryogenic Fracturing of Rock Specimens Under True Triaxial Confining Stresses. 78th EAGE Conference and Exhibition. Vienna, Austria.

5. Chang, H. (2004). Hydraulic Fracturing in Particulate Materials, PhD. Georgia Institute of Technology.

6. Daneshy, A. A. (1972). A Study of Inclined Hydraulic Fractures . SPE-AIME 47th Annual Fall Meeting, SPE 4062. San Antonio, TX.

7. Economides, M. J., Watters, L. T., \& Dunn-Norman, S. (1998). Petroleum Well Construction. In M. J. Economides, L. T. Watters, \& S. Dunn-Norman, Petroleum Well Construction (pp. 143-1712). John Wiley \& Sons.

8. Fisher, M. K., Heinze, J. R., Harris, C. D., Davidson, B. M., Wright, C. A., \& Dunn, K. P. (2004). Optimizing Horizontal Completion Techniques in the Barnett Shale Using Microseismic Fracture Modeling. SPE Annual Technical Conference and Exhibition, SPE 90051. Houston, TX.

9. Grandi, S., Rao, R. V., \& Toksoz, M. N. (2002). Geomechanical modeling of in-situ stresses around a borehole. Massachusetts Institute of Technology. Earth Resources Laboratory.

10. Hassler, G. L. (1945). Measurement of capillary pressures in small core samples. Transactions of the AIME, 160(01), 114-123.

11. Karimi, S., Kazemi, H., \& Simpson, G. A. (2017). Capillary Pressure, Fluid Distribution, and Oil Recovery in Preserved Middle Bakken Cores. SPE Oklahoma City Oil and Gas Symposium. Oklahoma City, OK.

12. Karimi, S., Saidian, M., \& Kazemi, H. (2016). Experimental Study of the Effect of Core Aging on Fluid Distribution in Middle Bakken Cores. SPE Low Perm Symposium, SPE 180269. Denver, CO. 
13. Karimi, S., Saidian, M., Prasad, M., \& Kazemi, H. (2015). Reservoir rock characterization using centrifuge and nuclear magnetic resonance: A laboratory study of middle bakken cores. SPE Annual Technical Conference and Exhibition, SPE 175069. Houston, TX.

14. King, S. R. (1983). Liquid CO2 for the stimulation of low-permeability reservoirs. SPE/DOE Low Permeability Gas Reservoirs Symposium, SPE 11616. Denver, CO.

15. Li, G., Allison, D., \& Soliman, M. Y. (2011). Geomechanical study of the multistage fracturing process for horizontal wells. 45th US Rock Mechanics/Geomechanics Symposium. San Francisco, CA: American Rock Mechanics Association.

16. Li, Q., Xin, H., Liu, J., \& Liu, X. (2015). A review on hydraulic fracturing of unconventional reservoir. Ke Ai - Advanced Research Evolving Science, Petroleum 1, 8-15.

17. Mayerhofer, M. J., Lolon, E. P., Warpinski, N. R., Cipolla, C. L., Waiser, D., \& Rightmire,, C. M. (2008). What is Stimulated Reservoir Volume? SPE Shale Gas Production, SPE 119890. Fort Worth, TX.

18. McDaniel, B. W., Grundmann, S. R., Kendrick, W. D., Wilson, D. R., \& Jordan, S. W. (1997). Field applications of cryogenic nitrogen as a hydraulic fracturing fluid. SPE Annual Technical Conference and Exhibition. San Antonio, TX.

19. Medeiros, F., Kurtoglu, B., Ozkan, E., \& Kazemi, H. (2007). Pressure-Transient Performances of Hydraulically Fractured Horizontal Wells in Locally and Globally Naturally Fractured Formations. International Petroleum Technology Conference.

20. Meiboom, S., \& Gill, D. (1958). Modified spin-echo method for measuring nuclear relaxation times. Review of scientific instruments, 29(8), 688-691.

21. Mokhtari, M., \& Tutuncu, A. N. (2016). Impact of Laminations and Natural Fractures on Rock Failure in Brazilian Experiments; A case study on Green River adn Niobrara Formations. Natural Gas and Science and Engineering, 36, 79-86.

22. Padin, A., Tutuncu, A. N., \& Sonnenberg, S. (2014). On the Mechanism of Shale Microfarcture Propagation. SPE Hydraulic Fractuirng Technology Conference, SPE 168624. Woodland, TX.

23. Ptaszynska, A., Green, S., Hupka, J., \& Suarez-Rivera, R. (2016). Mineral and Organic Matter Constituents in Weak Interfaces in Shales. 50th US Rock Mechanics/Geomechanics Symposium. Houston, TX: American Rock Mechanics Association.

24. Sepehri, J., Soliman, M. Y., \& Morse, S. M. (2015). Application of extended finite elementmethod to simulate hydraulic fracture propagation from orientedperforations. SPE 
Hydraulic Fracturing Technology Conference. Woodlands, TX.

25. Shah, S. N., Vincent, M. C., Rodriquez, R. X., \& Palisch, T. T. (2010). Fracture orientation and proppant selection for optimizing production in horizontal wells. SPE Oil and Gas India Conference and Exhibition, SPE 128612. Mumbai, India.

26. Soliman, M. Y., Daal, J., \& East, L. (2012). Impact of fracturing and fracturing techniques on productivity of unconventional formations. SPE/EAGE European Unconventional Resources Conference \& Exhibition. Vienna, Austria.

27. Soliman, M. Y., East, L. E., \& Augustine, J. R. (2010). Fracturing design aimed at enhancing fracture complexity. SPE EUROPEC/EAGE Annual Conference and Exhibition. Vienna, Austria.

28. Soliman, M. Y., East, L., \& Adams, D. (2004). GeoMechanic Aspects of Multiple Fratcuring of Harizontal and Vertical Wells. SPE International Thermal Operations and Heavy Oil Symposium, SPE 86992. Bakersfield, CA.

29. Sone, H., \& Zoback, M. D. (2013). Mechanical properties of shale-gas reservoir rocks_Part 1: Static and dynamic elastic properties and anisotropy. Geophysics, 78(5), D381-D392.

30. Sone, H., \& Zoback, M. D. (2013). Mechanical properties of shale-gas reservoir rocks-Part 2: Ductile creep, brittle strength, and their relation to the elastic modulus. Geophysics, 78(5), D393-D402.

31. Sonnenberg, S. (2014). The Upper Bakken Shale Resource Play, Williston Basin. Unconventional Resources Technology Conference, URTeC 1918895. Denver, CO.

32. Suarez-Rivera, R., Burghardt, J., Stanchits, S., Edelman, E., \& Surdi, A. (2013). Understanding the effect of rock fabric on fracture complexity for improving completion design and well performance. International Petroleum Technology, IPTC 17018. Beijing, China.

33. Veeken, C., Davies, D., \& Walters, J. (1989). Limited Communication Between Hydraulic Fracturing and (Deviated) Wellbore. SPE Joint Rocky Mountain Regional/Low Permeability Reservoirs Symposium and Exhibition. Denver, CO.

34. Veselinovic, D., Green, D., \& Dick, M. (2016). Determination of Natural Fracture Porosity Using NMR. Unconventional Resources Technology Conference, URTEC-2447768-MS.

35. Walton, I., \& McLennan, J. (2013). The Role of Natural Fractures in Shale Gas Production. International Society for Rock Mechanics.

36. Wu, R. (2006). Some Fundamental Mechanisms of Hydraulic Fracturing . Georgia Institute 
of Technology.

37. Xiong, Y., Fakcharoenphol, P., Winterfeld, P., Zhang, R., \& Wu, Y. S. (2013). Coupled geomechanical and reactive geochemical model for fluid and heat flow: application for enhanced geothermal reservoir. SPE Reservoir Characterization and Simulation Conference and Exhibition. Abu Dhabi, UAE.

38. Yao, B., Wang, L., Patterson, T., Kneafsey, T. J., Yin, X., \& Wu, Y. (2017). Experimental Study and Modeling of Cryogenic Fracturing Treatment of Synthetic Rock Samples Using Liquid Nitrogen under Tri-Axial Stresses. SPE Unconventional Resources Conference. Abu Dhabi, UAE.

39. Yao, B., Wang, L., Yin, X., \& Wu, Y. S. (2016). Numerical modeling of cryogenic fracturing process on laboratory-scale Niobrara shale samples. . Journal of Natural Gas Science and Engineering.

40. Zhang, R., Winterfeld, P. H., Yin, X., Xiong, Y., \& Wu, Y. S. (2015). equentially coupled THMC model for CO 2 geological sequestration into a 2D heterogeneous saline aquifer. Journal of Natural Gas Science and Engineering, 27, 579-615. 